\title{
THE I84-IN. CYCLOTRON AT BERKELEY, CALIFORNIA
}

\author{
By Prof, M. L. Oliphant, F.R.S.
}

$\mathrm{D}$ URING a recent trip to the United States in an official capacity, I was fortunate to be able to repeat for a few hours a visit I made first in 1938 to the Radiation Laboratory in Berkeley, California. The earlier visit was made with the object of obtaining information which would enable me to build in Birmingham a large cyclotron. The 60 -in. monster in the Crocker Laboratory was almost complete, and Lawrence had already begun to think of trying to push the cyclotron technique to its limit. We discussed in detail the difficulties of such a scheme, but these proved small obstacles in the path of Lawrence and his great band of co-workers. The theory of the cyclotron had recently been worked out, and it had been shown by the 'prophets' that existing apparatus which delivered 8-10 million volt deuterons was in fact the largest which could be made to work; owing to loss of resonance between the particles and the electric field due to relativistic change of mass. The Berkeley group under Lawrence promptly increased greatly the voltage applied to the electrodes of the new 60 -in. cyclotron and showed that no such limit need in fact exist.

In the realms of nuclear physics the cyclotron is by far the most powerful tool which we possess, and in its present form in Berkeley it provides curies of activity of artificially radioactive elements and weighable quantities of transmuted elements. The possibilities for medical and chemical investigation are only now being realized, and the chemistry of carbon itself in complex organic and biochemical changes is being studied by use of the short-lived active carbon isotope now available in large quantities. Elements as heavy as bismuth can be transmuted by bombardment with the existing apparatus.

The giant cyclotron now under construction contains enough steel and copper to build two large destroyers, and is designed to push the cyclotron technique to the extreme limit. It will be capable of providing particles with energies approaching those of cosmic rays, and we can expect with confidence that these will open up fresh fields in atomic physics. The Rockefeller Foundation and the United States are to be congratulated on the vision displayed in enabling the inventor of the most remarkable apparatus used in scientific in-

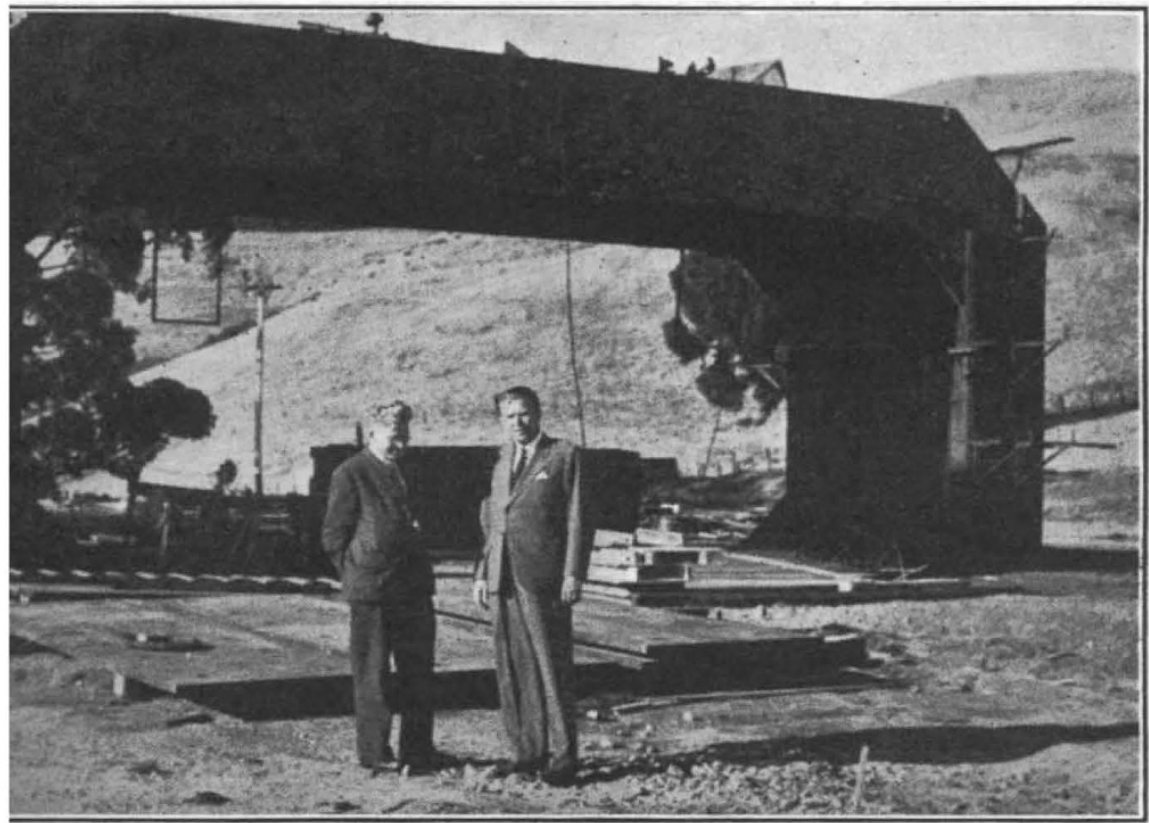

Magnet of the 184-in. Cyclotron Under construction at Berkeley, Californta. In the foreground are Prof. E. O. Lawrence (right) and Prof. M. L. Oliphant (left). Photograph by Dr. Donald Cooksey, assistant director of the Radiation Laboratory. vestigations the opportunity himself to direct the building of this great machine. Lawrence is assisted by a brilliant team of workers who have been associated with his work in the past. With Lawrence himself, many of these men are now doing work of more immediate national importance, but the project itself is proceeding under the guidance of Dr. Donald Cooksey, Lawrence's enthusiastic lieutenant.

It is certain that, when completed, the giant cyclotron will attract physicists from the whole world, and Lawrence expresses himself as the director of a piece of apparatus which will in happier times be shared by all who have the wish and the ability to do so. In front are the blue waters of San Francisco Bay; and behind, the warm hills scented by groves of eucalyptus trees. A physical centre of such importance in so beautiful 
a part of the earth will draw scientific workers from every country. In Berkeley with Lawrence there is much of the spirit of the Cavendish, and in Lawrence there is one who, like Rutherford, can gather round him a team of men and inspire them to do great things.

Dr. Donald Cooksey, who has forwarded the photograph reproduced herewith, showing Prof. Ernest O. Lawrence (right) and Prof. M. L. Oliphant (left), has sent the following particulars of the cyclotron and the laboratory which is being built to house it.

The magnet is $56 \mathrm{ft}$. long, $30 \mathrm{ft}$. high and $184 \mathrm{in}$. wide. It rests on 1,200 tons of concrete, contains 3,700 short tons of steel and 300 tons of copper.
The pole diameter will be 184 in., and the gap between the poles 40 in. The steel construction is complete except for the upper core and the pole tips.

The laboratory enclosing this magnet, which is about to be erected, will be a 24-sided building, on a spur overlooking the Berkeley campus and the whole of San Francisco Bay; in fact, it is directly opposite the Golden Gate, the elevation above sea-level being $881 \mathrm{ft}$. The views involved probably make it the most spectacular site for any physics laboratory in the world. The construction work has now been under way for about a year, and it is estimated that approximately two more years will be required for its completion. This cyclotron is being designed to give 100 million electron-volt deuterons.

\section{OB ITUARIES}

\section{Mr. H. M. Wallis}

Henry Marriage Wallis died on November 10 at the age of eighty-seven in Reading, where he had resided since 1872. He was a member of a well-known Quaker family from Ipswich. He had travelled widely in Europe and North Africa, spending each winter in and around the Mediterranean. He was 'father' of the Reading Museum and Art Gallery, with which institute he had been associated for half a century as the honorary curator of vertebrates.

As the result of a deep passion for, and love of, Nature, Wallis became known for his multitude of observations, especially on birds and mammals. His knowledge (based on first-hand experience) was profound and was passed on to his fellows by contributions to a number of seientific and other journals and to the Press and by lectures-the latter covering many branches of science and history.

Wallis corresponded with Darwin on the subject of the hair upon the ears of new-born babies. Wallis also did research work on ancient breods of pigs, having been stimulated by those he saw in Bulgaria and those depicted on Greek coins.

He was responsible for the acquisition of specimens of the British deer-red, fallow and roe (male, female and young of each)-from the herd of the late King George $V$ at Windsor, which now make the magnificent groups in Reading Museum. The birds of prey of the Pyrenees were a special study of his, and I am indebted to him for minute guidance to the avi-fauna of that region. Besides his study of local birds and mammals, Wallis took a leading part in the experiment in 1930 of introducing a colony of large copper butterflies in the Kennet valley.

$\mathrm{He}$ was a founder member of the Reading and District Natural History Society and was president during 1891-93. He was also a member of the
British Ornithological Union, the British Trust for Ornithology.

H. M. Wallis was a lovable and humble man and will be sadly missed by a multitude of friends, both personal and scientific. W. A. Smallcombe.

\section{Mr. Richard T. Baker}

WE regret to record the recent death in Australia of Mr. Richard T. Baker. For thirty years Baker was curator of the Technological Museum, Sydney, and for thirteen years lecturer in forestry at the University of Sydney. $\mathrm{He}$ is perhaps best known to botanists for his comprehensive work on the Coniferæ of Australia, published in 1910, in which he was assisted by Mr. H. G. Smith, assistant curator and economic chemist at the Technological Museum, Sydney. Mr. Smith also collaborated with him in his valuable researches on the genus Eucalyptus, (specially with reference to their essential oil, and the results were published in 1902 . The conifers were profusely illustrated by numerous photographs of the trees in situ and of herbarium specimens, as well as photomicrographs showing anatomical structure, some of them in the colours with which they had been stained.

Baker also published a large number of small papers on various Australian economic plants, and these are scattered through the volumes of the Journal and Proceedings of the Linnean Society of New South Wales. Nearly all of them are accompanied by firstrate black-and-white drawings by the author, with full details of the structure of the flowers and fruit.

Baker was a fellow of the Linnean Society of Now South Wales and served on the Council during 18971922. In 1922 he was awarded the Clarke Medal of the Royal Society of Now South Wales, of which he was elected a fellow in 1894. 